Article

\title{
Technical Assessment of Different Operating Conditions of an On-Board Autothermal Reformer for Fuel Cell Vehicles
}

\author{
Laura Tribioli *, Raffaello Cozzolino and Daniele Chiappini \\ Department of Engineering, Niccolò Cusano University, via Don Carlo Gnocchi 3, 00166 Rome, Italy; \\ raffaello.cozzolino@unicusano.it (R.C.); daniele.chiappini@unicusano.it (D.C.) \\ * Correspondence: laura.tribioli@unicusano.it \\ Academic Editor: Peter V. Schaeffer \\ Received: 28 April 2017; Accepted: 21 June 2017; Published: 23 June 2017
}

\begin{abstract}
This paper evaluates the performance of a fuel cell/battery vehicle with an on-board autothermal reformer, fed by different liquid and gaseous hydrocarbon fuels. A sensitivity analysis is performed to investigate the system behavior under the variation of the steam to carbon and oxygen to carbon ratios. This is done in order to identify the most suitable operating conditions for a direct on-board production of hydrogen to be used in a high temperature polymer electrolyte membrane fuel cell. The same system should be able to process different fuels, to allow the end-user to freely decide which one to use to refuel the vehicle. Hence, the obtained operating conditions result in a trade-off between system flexibility as the feeding fuel changes, $\mathrm{CO}$ poisoning effect on the fuel cell and overall efficiency. The system is thus coupled to a high temperature fuel cell, modeled by means of a self-made tool, able to reproduce the polarization curve as the input syngas composition varies, and the overall system is afterwards tested on a plug-in fuel cell/battery vehicle simulator, in order to provide a thorough feasibility analysis, focusing on the entire system efficiency. Results show that a proper energy management strategy can mitigate the effect of the fuel variation on the reformer efficiency, allowing for good overall powertrain performance.
\end{abstract}

Keywords: on-board hydrogen production; hydrocarbons autothermal reforming; high temperature proton exchange membrane (PEM) fuel cell; fuel cell vehicle

\section{Introduction}

The automotive sector is one of the main contributors to pollutant and global greenhouse gas emissions [1], and hybrid electric vehicles are gaining popularity thanks to the possibility of increasing the overall efficiency, lowering emissions and fuel consumption [2,3]. At the same time, fuel cell vehicles (FCVs) avoid the use of internal combustion engines, further reducing pollutant emissions [4]. As a matter of fact, high costs, low power density and lack of hydrogen infrastructures are the main drawbacks that still restrain the spread of these vehicles. Among these, the most critical aspect is probably the inadequate hydrogen production and distribution infrastructure, coupled with difficulties in setting it up properly and quickly. An on-board fuel processor for direct in-vehicle hydrogen conversion from hydrocarbon fuels is thus the only solution, in the short and mid term, to allow FCVs to conquer an acceptable market share [5]. This solution is attractive also for safety reasons: the whole system is less space-demanding than a compressed hydrogen tank and simplifies the refueling process, by exploiting existing infrastructure. In addition to this, unlike internal combustion engines that allow at most a bi-fuel operation, the same reformer can be fed by several fuels, requiring only the adaptation of the operating conditions, but keeping the processor unvaried and preserving the system integrity. 
A multi-fuel vehicle would guarantee a higher satisfaction level on the customer side, as it lets the end-user decide which fuel to use, depending on price and/or availability.

In 2001, Pettersson [6] proposed a state-of-the-art analysis on the performance of such a system, concluding that the cost of a fuel cell vehicle equipped with a multi-fuel reformer was too high for the level of technology available at that time. In the same year, Brown [7] reached similar conclusions in a comparative study of seven different automotive fuels for on-board hydrogen production for FCVs. In that study, the employed fuel processors were steam or partial oxidation reformers, coupled with low temperature polymer electrolyte membrane fuel cells (LTPEM FC), and the costs did not justify the efficiency trade-off required by a multi-fuel operation. The work in [8] compared systems powered by hydrogen and gasoline or methanol reformed on-board via partial oxidation, showing that the total infrastructure cost to society, including on-board fuel processors, was less for hydrogen than for either gasoline or methanol, with the technology available at the time. In the FCVs proposed in those studies and in other early prototypes $[9,10]$, the on-board hydrogen production had to fulfill the requirements of a fuel cell providing $100 \%$ of the vehicle traction power, causing reformer size and system costs that make the solution economically unfeasible. After a period of lack of interest on the topic, in the early 2010s, on-board fuel processing was investigated again for coupling with small fuel cells.especially used as auxiliary power units of $1-5 \mathrm{~kW}$ of rated power [11-13]. In those systems, the energy management of the vehicle was generally based on the operation of the fuel cell at constant power, derived from the stand-alone optimization of the autothermal reactor (ATR)/FC system efficiency. A system efficiency of $25.1 \%$ was estimated by [11], for an LTPEM FC fueled with methanol-derived hydrogen, while [13] obtained an overall ATR/FC system efficiency up to $41 \%$ with ethanol. Even claiming the possibility of using the system in-vehicle, those results were referred to a stand-alone system and were not tested under different driving conditions. Furthermore, in [5], a stand-alone hydrogen production unit from reforming of ethanol was simulated for on-board purposes.

There is no evidence in the literature of studies where the entire vehicle efficiency is evaluated by implementing the energy management of a fuel cell vehicle with a multi-fuel on-board processor and variable fuel cell load.

Moreover, on the fuel cell side, mobile applications are particularly attractive when the reformer is coupled to a high temperature polymer electrolyte membrane fuel cell (HTPEM FC), while studies available in the literature generally focus on on-board fuel processing for LTPEM FC [5,10,12]. A high reformate purity [14,15], with low CO content, is required to avoid poisoning of the cell membrane. This requirement would ask for a shift reactor and a CO preferential oxidation or selective methanation section, increasing the space required by the system [16]. On the contrary, HTPEM FCs have good CO-tolerance, thanks to operation temperatures of around $160-200{ }^{\circ} \mathrm{C}$, and have been already successfully tested for use in automobile applications with reformed liquid fuels $[11,13,17,18]$. With the use of HTPEM FCs, the complexity of the fuel processing line can be reduced, thus avoiding the parasitic losses of unnecessary components and the additional advantages of more effective stack cooling, due to the higher temperature gradient with the refrigerant, faster electrochemical reaction kinetics and a less complex management, as no humidification is required [19].

As on-board reforming of liquid fuels requires compactness and simple overall system management, the objective of the present work is to model and simulate the autothermal processor in order to keep the system as simple as possible, using waste heat streams to recover thermal energy and preheat air, water and fuel. The system is tested by means of a plug-in fuel cell/battery vehicle simulator, in order to provide a thorough feasibility analysis. The energy management strategy of the system is derived from a past work [20], and the aim of this investigation is to demonstrate that the trade-off required by a multi-fuel operation of the processor can be mitigated by a proper vehicle energy management. In Section 2.1, the system modeling and optimization are thoroughly described; in Section 2.2, the system operating conditions are determined for a proper coupling with a HTPEM FC, modeled by means of a self-made tool, able to reproduce the polarization curve as the input syngas 
composition varies, for in-vehicle operation; in Section 3, the overall system performance is evaluated and presented.

\section{System Description}

In this section, the system composed by the ATR and the HTPEM FC is presented; in the first part, the complete set of operating conditions, where the ATR can work while being fed with different fuels, is described, and the choice of the operating point as a function of imposed constraints is deeply analyzed. In the second part, different polarization and efficiency curves achievable from the fuel cell by varying the composition of feeding syngases are reported.

\subsection{Autothermal Reactor Modeling and Optimization}

In this section, the operating parameters of the autothermal reformer are varied in order to maximize the system efficiency for every analyzed hydrocarbon. The fuel processor is modeled by using Aspen Plus ${ }^{\mathrm{TM}}$ (v11.1, Aspen Technology Inc., Bedford, MA, USA), which is a commercial modeling tool for design, optimization and performance monitoring for chemical processes, already successfully employed by others for similar analyses [21-25]. Simulation with Aspen Plus allows predicting the behavior of a process using engineering relationships, such as mass and energy balances, chemical and phase balances and reaction kinetics. The estimation method, set in this analysis for calculating different thermodynamic properties, is the non-random two liquid (NRTL) model. This method correlates the activity coefficients of a compound, with its mole fractions in the liquid phase. It is frequently applied in the field of chemical engineering to calculate phase equilibrium.

The selected hydrocarbons are: methane $\left(\mathrm{CH}_{4}\right)$, propane $\left(\mathrm{C}_{3} \mathrm{H}_{8}\right)$ as a surrogate of liquefied petroleum gas (LPG), isooctane $\left(\mathrm{C}_{8} \mathrm{H}_{18}\right)$ as a surrogate of gasoline and n-hexadecane $\left(\mathrm{C}_{16} \mathrm{H}_{34}\right)$ as a surrogate of diesel. The identification of the most favorable thermodynamic conditions for the fuel conversion has involved the knowledge of the influence of the major operating parameters in order to isolate only those of real interest. The general reforming reaction mechanism can be written as:

$$
\mathrm{C}_{n} \mathrm{H}_{m}+\frac{n}{2} \mathrm{H}_{2} \mathrm{O}+\frac{n}{4} \mathrm{O}_{2}+\frac{3.77 n}{4} \mathrm{~N}_{2} \rightarrow \text { Products }
$$

where $\mathrm{C}_{n} \mathrm{H}_{m}$ represents a generic hydrocarbon formula. The only products considered in the global reaction (1) are $\mathrm{H}_{2}, \mathrm{CO}, \mathrm{CO}_{2}, \mathrm{CH}_{4}, \mathrm{C}(\mathrm{s})$ and $\mathrm{H}_{2} \mathrm{O}$. In order to obtain maximum hydrogen production, the reforming reaction should occur in two steps: the high-temperature step (reforming reaction), in which the fuel is converted into a gaseous mixture of $\mathrm{H}_{2}, \mathrm{CO}, \mathrm{CO}_{2}, \mathrm{CH}_{4}, \mathrm{C}(\mathrm{s})$ and unreacted $\mathrm{H}_{2} \mathrm{O}$; the low-temperature step (water gas shift reaction), in which $\mathrm{CO}$ reacts with $\mathrm{H}_{2} \mathrm{O}$ and generates $\mathrm{H}_{2}$ and $\mathrm{CO}_{2}$. The main components of the process are:

- Autothermal reactor (ATR): It is the reforming reactor in which the fuel is converted into a gaseous mixture of $\mathrm{H}_{2}, \mathrm{CO}, \mathrm{CO}_{2}$ and $\mathrm{H}_{2} \mathrm{O}$. The ATR is fed by fuel, steam and oxygen, and it is maintained under adiabatic conditions, so that no heat transfer occurs from or to it.

- Water gas shift reactor (WGSR): the water gas shift reactor (low temperature water shift reactor WGSR) in which $\mathrm{CO}$ is reacted with $\mathrm{H}_{2} \mathrm{O}$ towards $\mathrm{H}_{2}$ and $\mathrm{CO}_{2}$.

- Heat recovery line: Since the thermal efficiency of the fuel processor unit depends strongly on reactants' preheating temperatures, as reported in [26], a heat recovery line is defined by cooling the syngas stream temperature in two heat exchangers. In particular, the water and fuel required by the reforming reaction are pre-heated in the heat exchanger $\mathrm{HEX}_{2}$ by cooling the syngas stream and then heated in the heat exchanger $\mathrm{HEX}_{1}$; the oxygen sent to the autothermal reactor is already heated up to $351{ }^{\circ} \mathrm{C}$ because of the compression up to 10 bar required by the membrane separation process [20].

- Separation unit (SEP): the membrane separation unit where the pure oxygen is produced; here, the air is compressed up to $10 \mathrm{bar}$, and then, by passing through the membrane, the oxygen is separated from nitrogen with a $95 \%$ removal efficiency. 
- Inter-refrigerated compression line (IRCL): the syngas compression line, equipped with three compressors and two heat exchangers, needed in order to increase the syngas pressure up to the hydrogen buffer pressure, i.e., 250 bar [20].

All of the subsystems above described are synthetically reported in Figure 1, where a complete layout of the ATR system is depicted, providing also the main operating temperatures of the system.

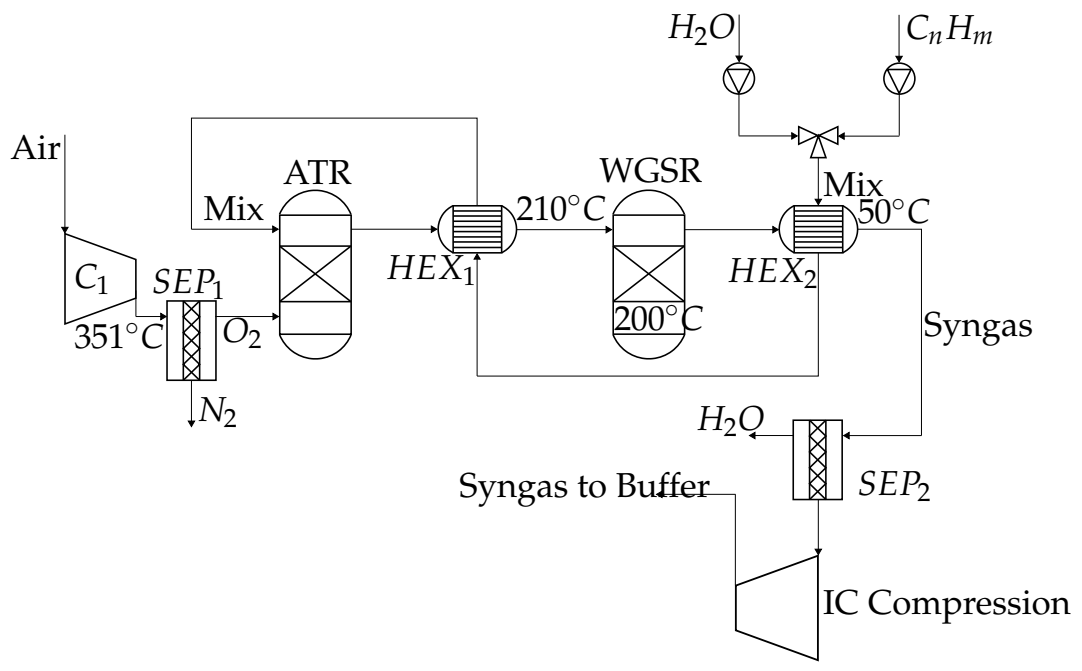

Figure 1. Autothermal reactor (ATR) system layout.

The thermodynamic equilibrium analysis is determined by the non-stoichiometric approach, due to the complexity of the reaction system. In this approach, the equilibrium composition of the system is found by the direct minimization of the Gibbs free energy for a given set of species without any specification of the possible reactions that might take place in the system [20]. Thus, it is assumed that the carbon in the fuel is reformed only to $\mathrm{CH}_{4}, \mathrm{CO}$ or $\mathrm{CO}_{2}$ and $\mathrm{C}(\mathrm{s})$.

The following relation is used by the Gibbs reactor to solve the direct minimization of the Gibbs free energy for a given set of $N$ species:

$$
n G=\sum_{i=1}^{N} n_{i} \bar{G}_{i}=\sum n_{i} G_{i}^{0}+R T \sum n_{i} l n \frac{f_{i}^{*}}{f_{i}^{0}}
$$

where $n G$ is the total Gibbs free energy of the system, $n_{i}$ is the number of moles of species $i, \bar{G}_{i}$ is the Gibbs free energy pure species $i$ in the gas mixture, $g_{i}^{0}$ is the Gibbs free energy of species $i$ at its standard state, $R$ is the constant of gas, $T$ is the temperature of the system, $f_{i}^{*}$ is the fugacity of species $i$ in the gas mixture and $f_{i}^{0}$ is the fugacity of species $i$ at its standard state. The fugacity of species $i$ in the gas mixture is calculated by:

$$
f_{i}^{*}=\phi_{i}^{*} y_{i} P
$$

where $\phi_{i}^{*}$ is the fugacity coefficient of species $i$ in the gas mixture, $y_{i}$ is the mole fraction of species $i$ and $P$ is the total pressure of the system.

The fugacity $f_{i}^{0}$ of species $i$ at its standard state is equal to one bar. For each chemical element, $G_{i}^{0}$ is set equal to zero in its standard state; therefore, $G_{i}^{0}=\Delta G_{f i}^{0}$ for each component, where $\Delta G_{f i}^{0}$ is the standard Gibbs free energy of the formation of species $i$. Replacing these relationships in the above equation, we obtain:

$$
n G\left(n_{i}, s, T, P\right)=\sum n_{i} \Delta G_{f i}^{0}+\sum n_{i} R T \ln P+\sum n_{i} R T \ln y_{i}+\sum n_{i} R T \ln \phi_{i}^{*}
$$

The problem is solved by finding set of values that minimize $n G$ at constant temperature $T$ and pressure $P$. 
The equilibrium compositions have been calculated for a given operating condition, and in order to determine the thermal efficiency, the mass and energy balances are solved for each configuration. The conversion efficiency of the ATR system can be written as:

$$
\eta_{\mathrm{ATR}}=\frac{n_{\mathrm{H}_{2}} \cdot \mathrm{LHV}_{\mathrm{H}_{2}}}{n_{\mathrm{C}_{n} \mathrm{H}_{m}} \cdot \mathrm{LHV}_{\mathrm{C}_{n} \mathrm{H}_{m}}}
$$

where $n_{\mathrm{H}_{2}}(\mathrm{~mol} / \mathrm{s})$ is the number of moles of hydrogen produced, $n_{C_{n} \mathrm{H}_{m}}(\mathrm{~mol} / \mathrm{s})$ the number of moles of fuel consumed and $\mathrm{LHV}_{\mathrm{H}_{2}}(\mathrm{~J} / \mathrm{mol})$ and $\mathrm{LHV}_{\mathrm{C}_{n} \mathrm{H}_{m}}(\mathrm{~J} / \mathrm{mol})$ the higher heating value of hydrogen and fuel, respectively. In order to identify the thermodynamically-favorable operating conditions of the ATR system for the maximum efficiency production, a sensitivity analysis has been carried out by varying:

- the steam to carbon ratio S/C at the autothermal reactor, defined as the ratio between the mole flow rate of the steam fed to the reactor and the carbon mole flow rate of the feeding fuel, in the range of 0.2-3.6.

- the oxygen to carbon ratio $\mathrm{O} / \mathrm{C}$ at the autothermal reactor, defined as the ratio between the mole flow rate of the oxygen fed to the reactor and the carbon mole flow rate of the feeding fuel, in the range of $0.02-0.26,0.3-0.7,1.3-1.7$ and $2.5-3.5$, for methane, propane, isooctane and n-hexadecane respectively.

- the pre-heat temperature of fuel and water feeding the autothermal reactor, recovering the heat internally to the process.

Moreover, for every considered fuel, the inlet mass flow has been fixed in order to guarantee two power levels (respectively $16 \mathrm{~kW}$ and $40 \mathrm{~kW}$ ) as reported in Table 1.

Table 1. Mass flow rates in $(\mathrm{g} / \mathrm{s})$ for different feeding fuels.

\begin{tabular}{ccc}
\hline ATR Power & $\mathbf{1 6} \mathbf{k W}$ & $\mathbf{4 0} \mathbf{k W}$ \\
\hline Methane & 0.320 & 0.800 \\
Propane & 0.344 & 0.862 \\
Isooctane & 0.357 & 0.894 \\
N-hexadecane & 0.363 & 0.909 \\
\hline
\end{tabular}

In a previous study [27], carried out to predict the thermodynamically carbon-free region of reforming operations, the presence of solid carbon in the ATR has been found to depend strongly on the value of S/C and on reforming temperature. This carbon deposition is highly undesirable because, in addition to decreasing the process efficiency, it deactivates the catalyst. On the basis of this analysis, the S/C molar ratios considered here, for each reforming temperature, are those at which carbon deposition is avoided. In the following analysis, it will be shown that not all of the evaluated operating points avoid this undesirable effect. Thus, they will not be considered while deriving the ATR operating maps for every fuel. In fact, starting from the results of this analysis, the ATR working maps may be built, where all of the possible operating conditions are reported. Among these data, the point representing the best compromise between ATR conversion efficiency and CO concentration can be determined: the first parameter is crucial to maximize the $\mathrm{H}_{2}$ mass flow to the buffer, which feeds the fuel cell, while the latter one needs to be under control in order to maximize the fuel cell efficiency itself. Thus, in order to find a range of admissible working points, some constraints, used to reach the right trade-off between conversion efficiency and carbon monoxide concentration, have been carefully setup. As already pointed out, one of the constraints is related to the $\mathrm{CO}$ concentration in the syngas. As a matter of fact, the higher the $\mathrm{CO}$ concentration is, the worse the fuel cell operates. It has been already demonstrated $[14,15]$ that the HTPEM FC performances are strongly penalized when the $\mathrm{CO}$ concentration in the feeding gas overtakes a threshold equal to $2 \%$, which has been chosen in this work, in order to limit CO poisoning in the fuel cell. In addition, the limit on the S/C ratio is related to the CO poisoning, as well; as one may observe from Figure 1, following the ATR, there is 
a water separator to remove all of the water present in the syngas exiting the reforming section and sent to the hydrogen buffer. It may be trivially pointed out that the higher the $\mathrm{S} / \mathrm{C}$ ratio is, the greater the water concentration in the syngas results. As a consequence, all of the molar fractions of syngas species have to be re-evaluated after water separation with obvious penalization in terms of carbon monoxide concentration, surely increased after water removal from syngas. This is the reason why the maximum S/C ratio has been imposed equal to 1.5. With imposing these constraints, a subset of admissible working conditions can be extrapolated, from the whole range of results derived from the sensitivity analysis previously described. Moreover, among these admissible points, those falling in the carbon deposition area turn into non-admissible ones. Both conversion efficiency and temperature maps for all of the fuels considered in this analysis have been drawn, and in order to show the effect of these constraints, Figures 2 and 3 show the complete maps together with the subsets of admissible and non-admissible conditions. In those figures, the yellow points represent the possible working conditions, while the black points are the ones where carbon deposition occurs and must be excluded from the ATR operation. As expected, different fuels make the ATR operate in a different manner, leading to a strong variation of conversion efficiency and operating temperature as a function of the control parameters. In Figure 2, it is possible to observe how the temperature maps have different slopes and curvature as the fuel changes. More specifically, the fewer the carbon atoms in the fuel are, the steeper the maps result. This, of course, has influence on the extension of the admissible subset one can consider for every fuel. Figure 2a shows a series of points distributed in the steepest part of the map, while for n-hexadecane, Figure $2 \mathrm{~d}$, the temperature rise is definitely less influenced by the variation of the $\mathrm{S} / \mathrm{C}$ and $\mathrm{O} / \mathrm{C}$ ratios.

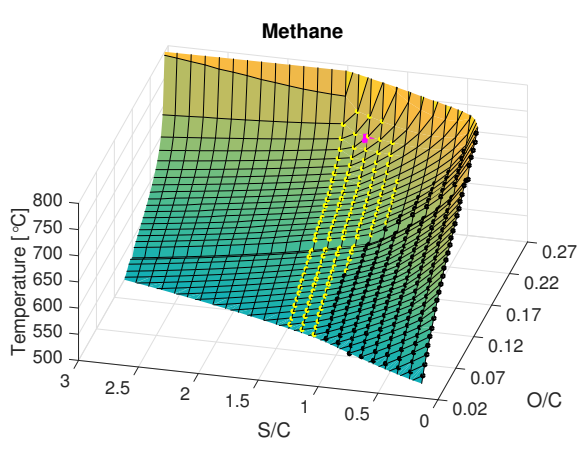

(a)

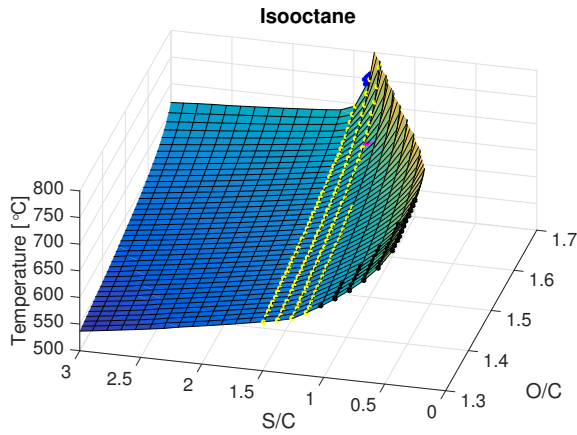

(c)

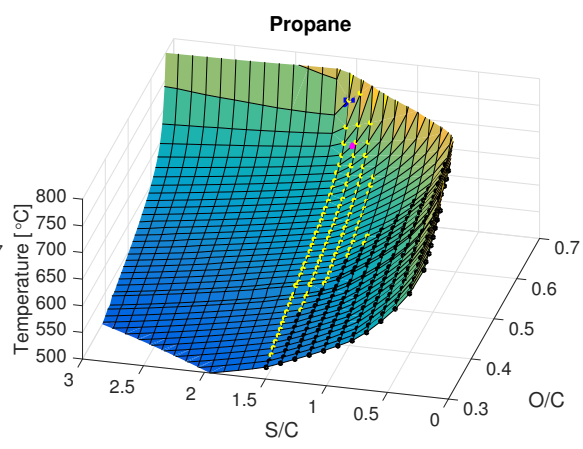

(b)

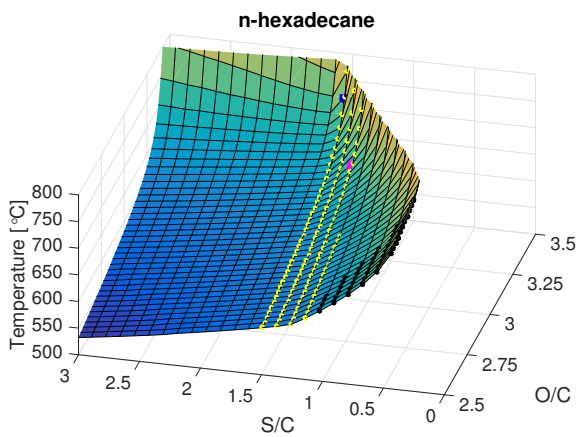

(d)

Figure 2. Temperature maps for different fuels with subset of admissible working points (yellow marker), subset of points where the carbon deposition occurs (black marker), chosen points at $700{ }^{\circ} \mathrm{C}$ (magenta marker) and at $750{ }^{\circ} \mathrm{C}$ (blue marker, if present). (a) Methane; (b) propane; (c) isooctane; and (d) n-hexadecane. 


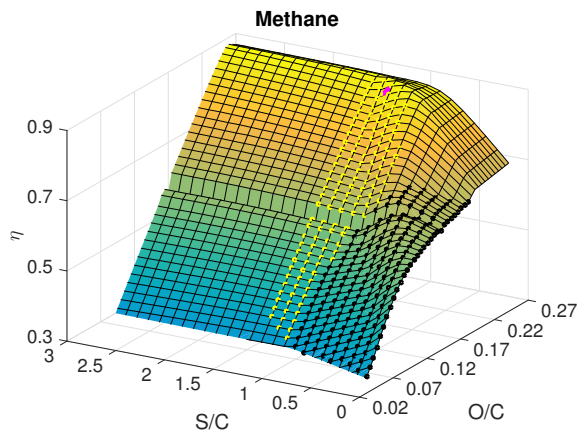

(a)

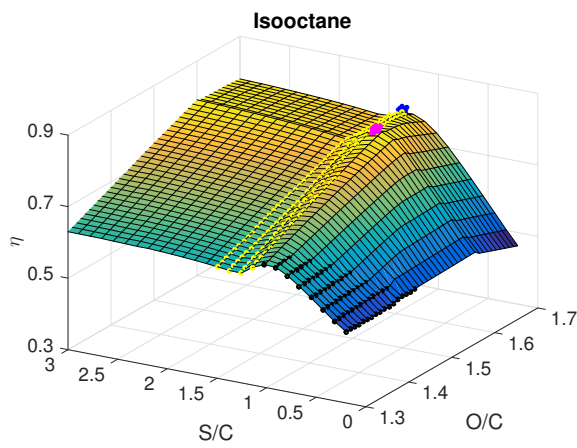

(c)

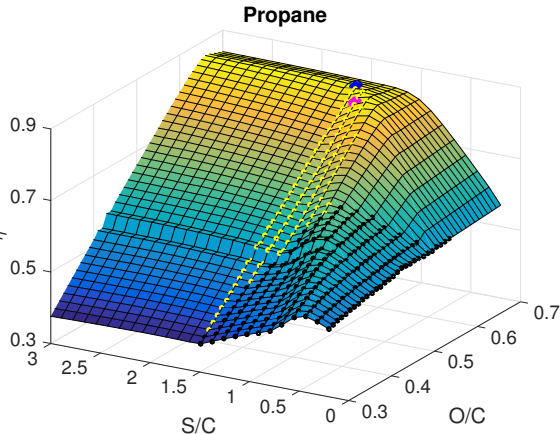

(b)

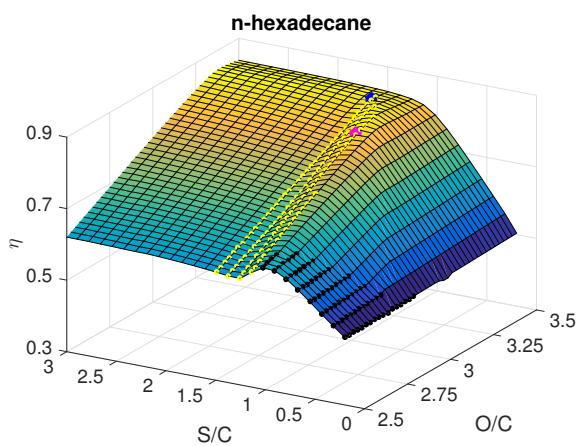

(d)

Figure 3. Conversion efficiency maps for different fuels with the subset of admissible working points (yellow marker), the subset of points where the carbon deposition occurs (black marker), chosen points at $700{ }^{\circ} \mathrm{C}$ (magenta marker) and at $750{ }^{\circ} \mathrm{C}$ (blue marker, if present). (a) Methane; (b) propane; (c) isooctane; and (d) n-hexadecane.

By looking at the conversion efficiency maps, a similar trend can be recognized as well. Also in this case, as for the temperature, a surface slope somehow related to the number of carbon atoms present into the fuel is observable. In Figure 3, the conversion efficiency maps with the subset of working points fulfilling the constraints and, again, the unusable carbon deposition area are depicted.

By analyzing Figures 2 and 3, it is possible to point out that there are several points that would satisfy the constraints. Obviously, in an on-board application, none can deal with such a high number of degrees of freedom for a component like the ATR. This is the reason why only two temperature levels where the ATR can operate have been considered. More specifically, $700{ }^{\circ} \mathrm{C}$ and $750{ }^{\circ} \mathrm{C}$, corresponding to the best compromise between conversion efficiency and $\mathrm{CO}$ concentration, have been chosen. Therefore, for every fuel, an operating point for each of those temperatures has been found, which meets the constraints on S/C and CO concentration previously described. Only methane cannot operate at $750{ }^{\circ} \mathrm{C}$; thus, for this temperature level, the analysis has been carried out only for three hydrocarbons (propane, isooctane and n-hexadecane). Figures 2 and 3 also report the operating points resulting from this analysis (magenta and blue markers). It is worth noting that the chosen points lie in the maximum conversion efficiency area for all of the configurations, albeit not coinciding with the maximum conversion efficiency value. The following Table 2 reports $\mathrm{S} / \mathrm{C}$ and $\mathrm{O} / \mathrm{C}$ ratios related to the operating conditions, as well as the evaluated conversion efficiency and the CO concentration. 
Table 2. Steam to carbon ratio $(\mathrm{S} / \mathrm{C})$, oxygen to carbon ratio $(\mathrm{O} / \mathrm{C})$ and conversion efficiency related to operating conditions for each hydrocarbon.

\begin{tabular}{ccccccccc}
\hline & \multicolumn{4}{c}{$\boldsymbol{T}=\mathbf{7 0 0}{ }^{\circ} \mathbf{C}$} & \multicolumn{5}{c}{$\boldsymbol{T}=750{ }^{\circ} \mathbf{C}$} \\
\hline Fuel Type & S/C & O/C & $\eta \%$ & $\mathbf{C O} \%$ & S/C & O/C & $\boldsymbol{\eta} \%$ & $\mathbf{C O} \%$ \\
\hline Methane & 1.2552 & 0.2450 & 84.81 & 0.74 & - & - & - & - \\
Propane & 1.3724 & 0.6300 & 82.70 & 0.82 & 1.4897 & 0.6600 & 84.43 & 0.61 \\
Isooctane & 1.2000 & 1.600 & 80.03 & 1.89 & 1.3724 & 1.700 & 77.44 & 0.91 \\
n-hexadecane & 1.2552 & 3.1750 & 81.22 & 1.51 & 1.4897 & 3.400 & 83.38 & 0.64 \\
\hline
\end{tabular}

In order to justify the impossibility to find an operating point at $750{ }^{\circ} \mathrm{C}$ for methane, the maximum ATR equilibrium temperature for all of the hydrocarbons in the subset of admissible working points can be evaluated, and a curve where the maximum temperature is depicted as a function of the number of carbon atoms of the fuel can be built.

Figure 4 clearly shows how the maximum temperature reached when methane feeds the ATR is significantly lower than the one reached when other fuels are used. In fact, for methane, a maximum temperature of about $735^{\circ} \mathrm{C}$ can be achieved, while the other fuels reach temperatures above $770{ }^{\circ} \mathrm{C}$. This implies the impossibility to feed the ATR by methane at $750{ }^{\circ} \mathrm{C}$.

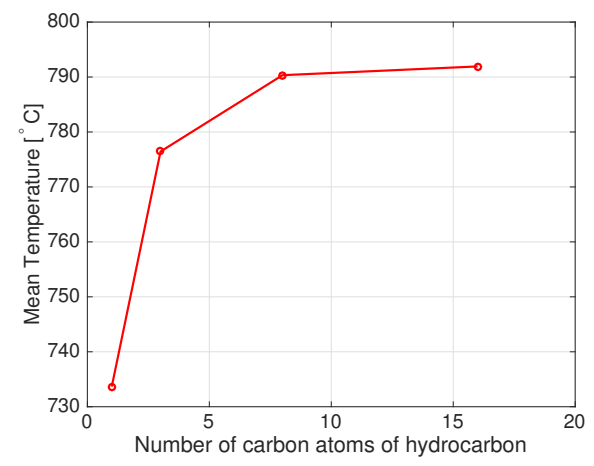

Figure 4. Maximum ATR equilibrium temperature as a function of number of carbons of the considered fuels.

The syngas compositions obtained with the working points presented in Table 2 are reported in Table 3. These compositions will be used in the following section as operating points for the fuel cell for every considered fuel.

Table 3. Syngas composition in terms of molar fractions obtained for the four fuels at two temperature levels.

\begin{tabular}{ccccccccc}
\hline \multicolumn{4}{c}{$T=\mathbf{7 0 0}{ }^{\circ} \mathbf{C}$} \\
Species & Methane & Propane & Isooctane & n-Hexadecane & Methane & Propane & Isooctane & n-Hexadecane \\
\hline $\mathrm{H}_{2}$ & 0.735 & 0.698 & 0.677 & 0.675 & - & 0.702 & 0.683 & 0.680 \\
$\mathrm{CO}$ & 0.00842 & 0.00894 & 0.01946 & 0.01543 & - & 0.00684 & 0.00987 & 0.00722 \\
$\mathrm{CO}_{2}$ & 0.241 & 0.279 & 0.287 & 0.295 & - & 0.283 & 0.299 & 0.304 \\
$\mathrm{CH}_{4}$ & 0.00902 & 0.00753 & 0.00969 & 0.00801 & - & 0.00142 & 0.00170 & 0.00129 \\
$\mathrm{~N}_{2}$ & 0.00656 & 0.00653 & 0.00685 & 0.00656 & - & 0.00674 & 0.00689 & 0.00700 \\
\hline
\end{tabular}

In the following, since the analysis is devoted to compare the performance of commercial fuels, for an easier comparison, the term LPG will be used instead of propane, gasoline instead of isooctane and diesel instead of n-hexadecane, while methane is kept unchanged. 


\subsection{High Temperature Polymer Electrolyte Membrane Fuel Cell}

In this section, the HTPEM FC response to different syngases is briefly described. The complete model has been already presented by the authors in other works $[14,15,20]$. The most important thing to point out here is, again, the strong dependency of the fuel cell behavior to $\mathrm{CO}$ poisoning. In fact, once having fixed other operating parameters, i.e., temperature and pressure, the polarization curve coming from the cell may significantly vary according to carbon monoxide concentration in feeding syngas. As deeply analyzed in the previous section, different concentrations for every considered hydrocarbon and for every ATR working temperature are obtained. As deeply explained in previous works, a semi-empirical model has been built where the cathode activation overpotential losses $\eta_{a c t, c a}$ are modeled by means of a multiple linear regression technique starting from a set of experimental data measured at different $\mathrm{CO}$ concentration. This analysis leads to the derivation of a semi-empirical formula where the tuning parameters $\beta_{z}$ are present:

$$
\eta_{a c t, c a}=\beta_{1}+\beta_{2} T+\beta_{3} T \ln \left(c_{O_{2}}\right)+\beta_{4} T \ln (i)
$$

where $\beta_{z}$ with $z \in[1,4]$ are the tuning parameters, $T$ is the operating fuel cell temperature, $i$ is the current density and $c_{\mathrm{O}_{2}}$ is the oxygen concentration at the cathode membrane/gas interface. The operating parameters of the fuel cell used in this analysis are briefly summarized in Table 4 .

Table 4. Operating conditions for high temperature polymer electrolyte membrane fuel cell (HTPEM FC).

\begin{tabular}{ccc}
\hline Operating Temperature & {$\left[{ }^{\circ} \mathrm{C}\right]$} & 160 \\
Utilization Factor $U_{F}$ & - & 0.8 \\
Anode Pressure, $p_{a}$ & {$[\mathrm{~atm}]$} & 1.3 \\
Cathode Pressure, $p_{c}$ & {$[\mathrm{~atm}]$} & 1.3 \\
Fuel Stoichiometry, $\lambda_{A n}$ & - & 1.2 \\
Air Stoichiometry, $\lambda_{\text {Cat }}$ & - & 2 \\
\hline
\end{tabular}

With respect to Tables 3 and 4, two sets of polarization curves have been obtained, one referred to as an ATR operating temperature of $700{ }^{\circ} \mathrm{C}$, where all four considered fuels are present, and one related to $750{ }^{\circ} \mathrm{C}$, where only three fuels can be used, it being impossible to find an operating point for methane. More specifically, Figure 5 shows the polarization and the power curves obtained for the lower temperature level, while in Figure 6, the same curves obtained with the higher temperature level are depicted.
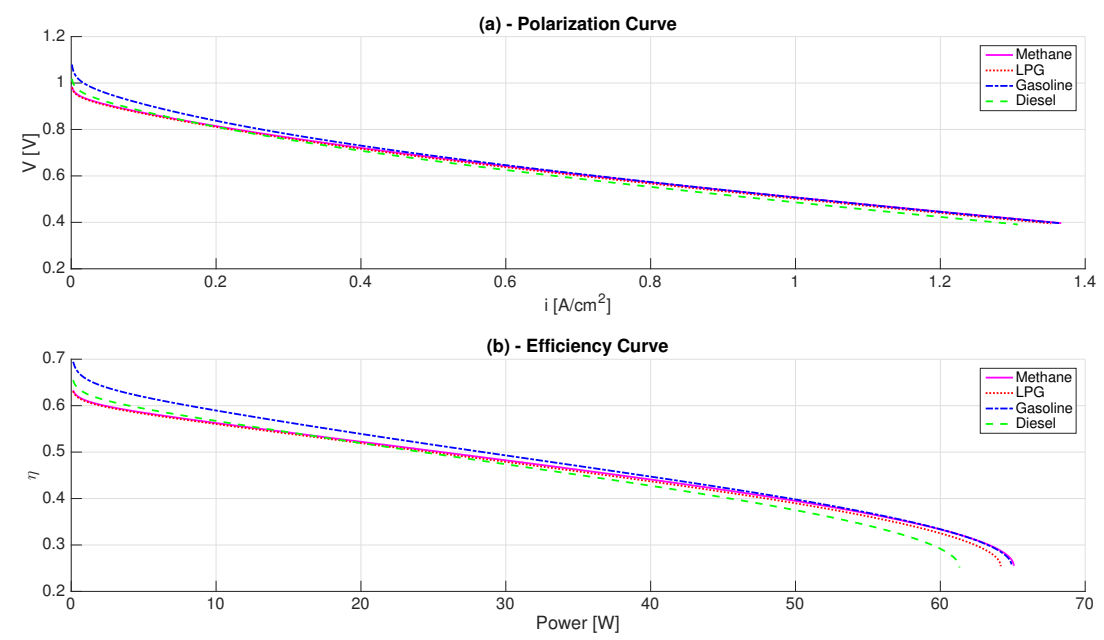

Figure 5. Polarization and power curves for the HTPEM FC with ATR operating at $700{ }^{\circ} \mathrm{C}$ and syngas compositions reported in Table 3. 


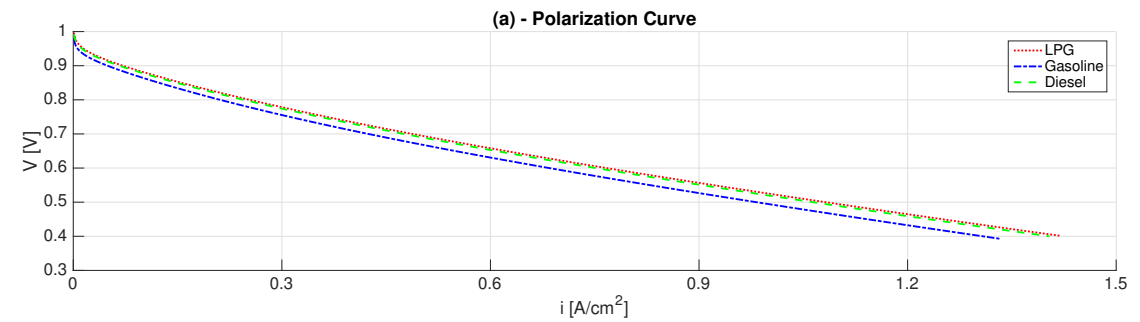

(b) - Efficiency Curve

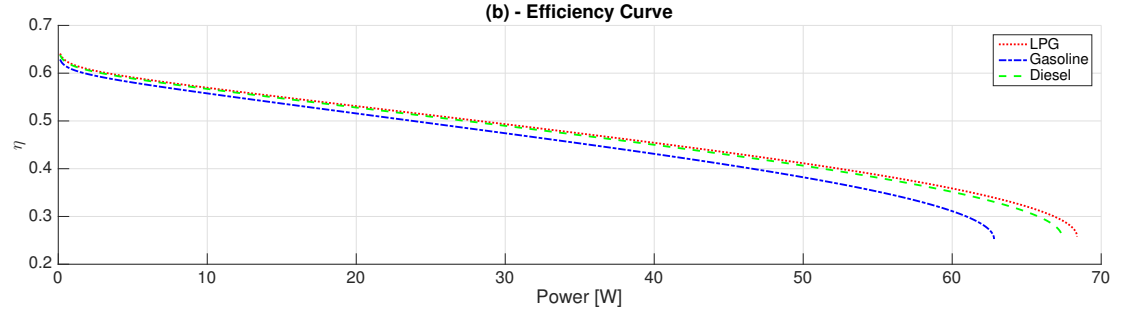

Figure 6. Polarization and power curves for the HTPEM FC with ATR operating at $750{ }^{\circ} \mathrm{C}$ and syngas compositions reported in Table 3.

\section{Application to a Fuel Cell/Battery Vehicle}

The vehicle simulator has been already described in a previous work [20], and therefore, its description is skipped here for the sake of fluency.

The system behavior and performance have been investigated by carrying out a sensitivity analysis, varying the driving conditions, the fuel type, the ATR size and operating temperature and the initial buffer level. In particular, the following driving cycles have been considered (see Figure 7):

- Artemis urban, urban driving cycle, for a total length of $50 \mathrm{~km}$;

- Extra-urban driving cycle, hereafter called Vail2NREL, for a total length of $140 \mathrm{~km}$;

- Federal Highway Driving Schedule (FHDS), highway driving cycle, for a total length of $250 \mathrm{~km}$;

- Worldwide harmonized Light vehicles Test Cycle (WLTC), combined driving cycle, for a total length of $180 \mathrm{~km}$.
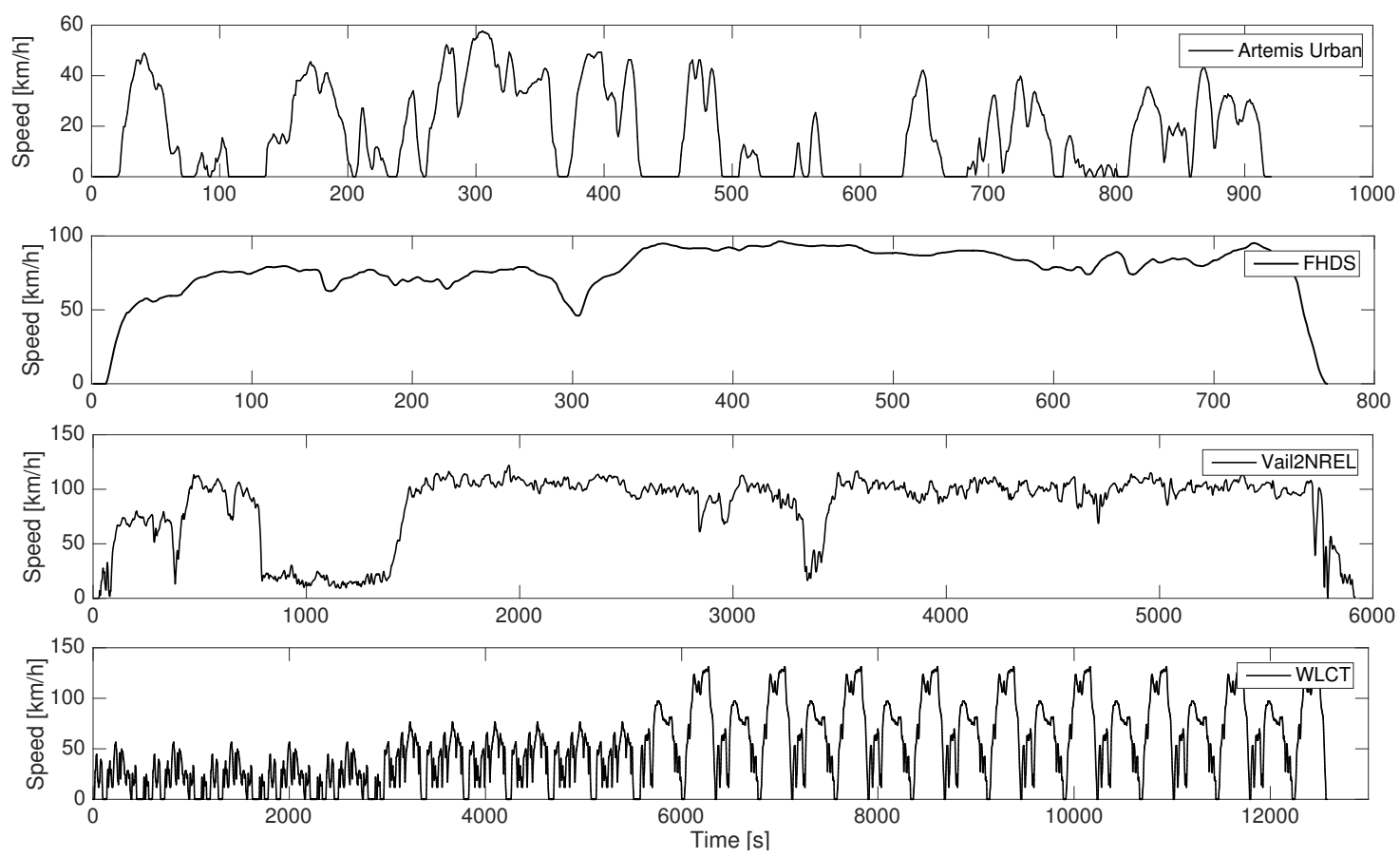

Figure 7. Driving cycles speed traces. 
For the reformer temperature, $700{ }^{\circ} \mathrm{C}$ and $750{ }^{\circ} \mathrm{C}$ were considered for the reasons explained in Section 2. For the size, a 16-kW ATR and a 40-kW ATR were considered, while the initial hydrogen buffer levels $\left(T_{0}\right)$ were set equal to $1 \mathrm{~kg}$ and $0.8 \mathrm{~kg}$. A value of at least $0.8 \mathrm{~kg}$ is chosen to face the 1200-s warm up time imposed for the ATR. These different initial buffer levels were set to test the assumption made of keeping the hydrogen amount produced by the reformer constant during each driving mission. This choice was made to overcome one of the greatest issues in the control of such a system, which is to maintain the temperatures of the reactors constant. Moreover, this allows keeping the fuel processor efficiency constant, as well. The presence of a buffer is thus needed to guarantee the necessary amount of hydrogen, by decoupling the FC from the ATR. This system layout also allows one to maintain a proper $\mathrm{H}_{2}$ level on the anode of the stack, preventing FC damages caused by starvation, and hydrogen is not wasted by overfeeding [28].

As the proposed FCV is a plug-in vehicle, it is known that the fuel consumption is minimized when the battery reproduces a blended operation, which gradually discharges the battery until a minimum state of charge $(S O C)$ threshold [29]. This threshold is generally set equal to $20-30 \%$, as the battery internal resistance highly increases when the SoC drops down below 20\%, decreasing the system efficiency and causing premature wear or damage. In [20], the lower threshold has been set equal to $30 \%$, and the supervisory control strategy tries to reproduce a blended battery depletion in order to reach this value, and in any case, it tries to maintain it (charge sustaining operation) until the end of the driving cycle. A further discharging of the battery is allowed only if there is no more hydrogen in the buffer or if the FC power is not sufficient to fulfil the driver's power demand, but in any case, the battery is never discharged below $15 \% \mathrm{SoC}$. In the charge sustaining operation, the fuel cell is run at high load in order to recharge the battery and give traction power, causing a decrease of the average efficiency. At the same time, if the driving cycle is particularly of low demand and the ATR is able to completely replenish the hydrogen buffer, the reactor is switched off. Nevertheless, in order to avoid a complete cool down, the switch-off phase duration lasts no more than $10 \mathrm{~min}$, and after this period, if the buffer is still full, the FC alone is used so as to consume hydrogen. On the contrary, if the driving cycle is particularly of high demand and the ATR is not able to prevent the complete emptying of the buffer, the FC is switched off, and the battery only supplies power to the wheels.

In [20], it has been seen that, in terms of fuel consumption, ending the driving cycle with a final state of charge $\left(\mathrm{SoC}_{\text {final }}\right)$ higher than $30 \%$ is more penalizing than ending the driving cycle with a charge sustaining operation. As one can note in Figure 8, in fact, the 40-kW ATR results in being oversized, and the controller is not able to discharge the battery. This is because the fuel cell is frequently forced to run alone to discharge the buffer, decreasing the fuel cell average efficiency $\eta_{F C}$ and therefore the system overall efficiency $\eta_{\text {overall }}$ (the system average overall efficiency is evaluated as the ratio between the total energy required by the traction motor and the sum of the input energies: battery energy and hydrocarbon fuel chemical energy). The higher the final state of charge, the lower the average overall efficiency is; therefore, an initial tank level of $1 \mathrm{~kg}$ further penalizes the system, as the fuel cell must be more frequently used. For the 16-kW ATR, the controller is always able to complete the driving mission with a $30 \%$ final $S o C$, but again, the overall efficiency is higher when the tank level is initially equal to $0.8 \mathrm{~kg}$. In particular, the overall efficiency is higher by more than 10 percentage points with respect to the $40-\mathrm{kW}$ ATR scenarios. Setting a $700{ }^{\circ} \mathrm{C}$ temperature for the reactor includes the possibility of using methane, but slightly decreases the efficiency of the system for the other fuels, even if never more than two percentage points.

In Figure 9, the results are proposed for the Vail2NREL. In this case, the 40-kW ATR seems to be sufficient enough to accomplish the driving mission in any condition, even if discharging the battery below $30 \%$. On the contrary, with the 16-kW ATR, the mission can be accomplished only if the tank is full. As one can note, for the $700{ }^{\circ} \mathrm{C}$ case, the diesel has the worst performance both in terms of average fuel cell efficiency and average overall efficiency. In fact, Figure 5 shows that the diesel-derived syngas has the lowest efficiency curve. Gasoline allows for the highest fuel cell average efficiency, but having the lowest conversion efficiency, the overall performance is slightly lower than LPG and methane. 
The best performance is for those of methane, which has a good average fuel cell efficiency and the highest conversion efficiency. In terms of hydrogen consumption, this translates into $10.82 \mathrm{~g} / \mathrm{km}$ consumed of gasoline-derived hydrogen, $11.08 \mathrm{~g} / \mathrm{km}$ for diesel-derived hydrogen, $11.02 \mathrm{~g} / \mathrm{km}$ for LPG-derived hydrogen and $10.97 \mathrm{~g} / \mathrm{km}$ for methane-derived hydrogen.

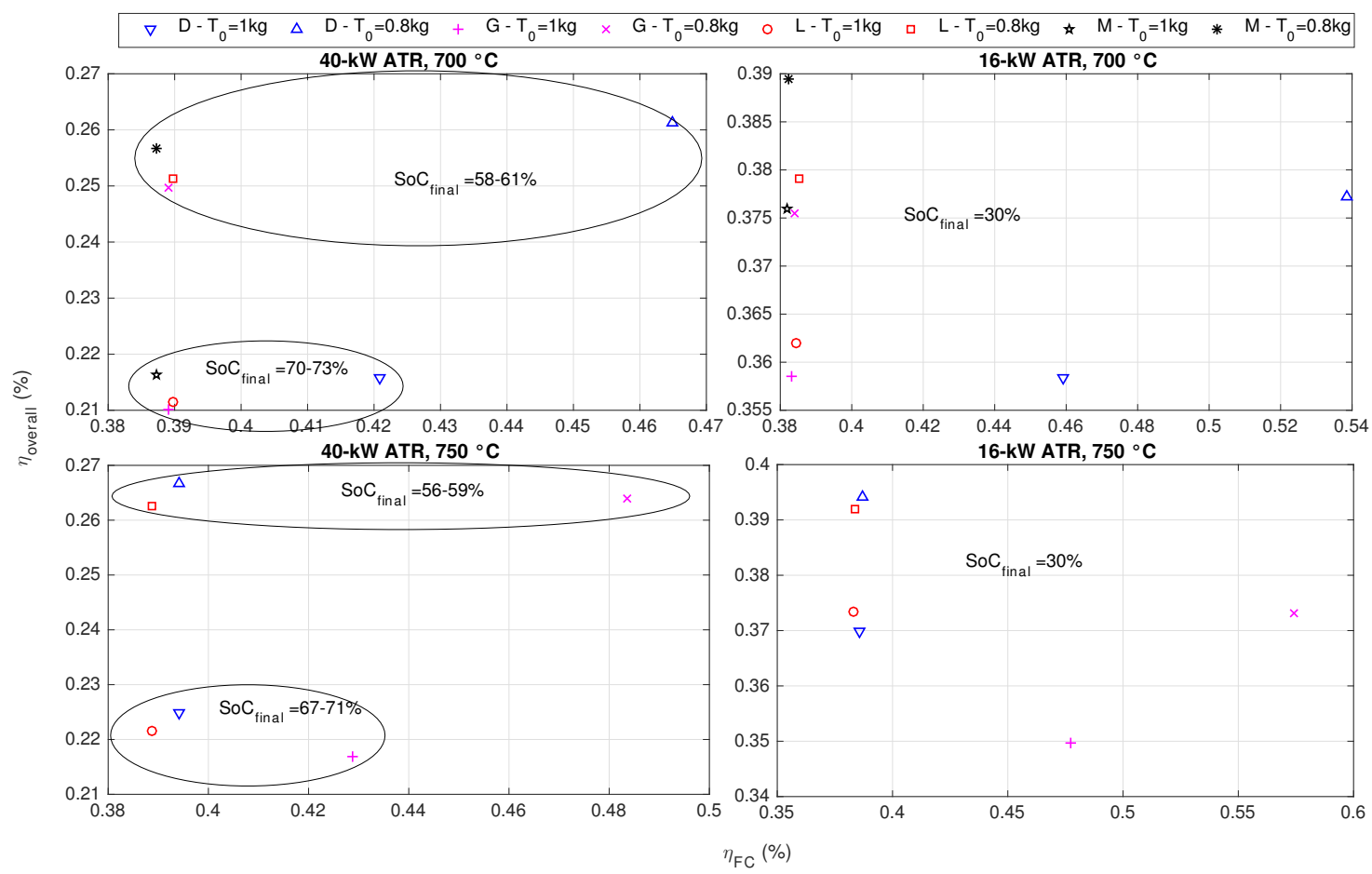

Figure 8. Artemis urban: urban driving cycle, total length $50 \mathrm{~km}$. In the legend, $\mathrm{D}=$ diesel, $\mathrm{G}=$ gasoline, $\mathrm{L}=\mathrm{LPG}, \mathrm{M}=$ methane.
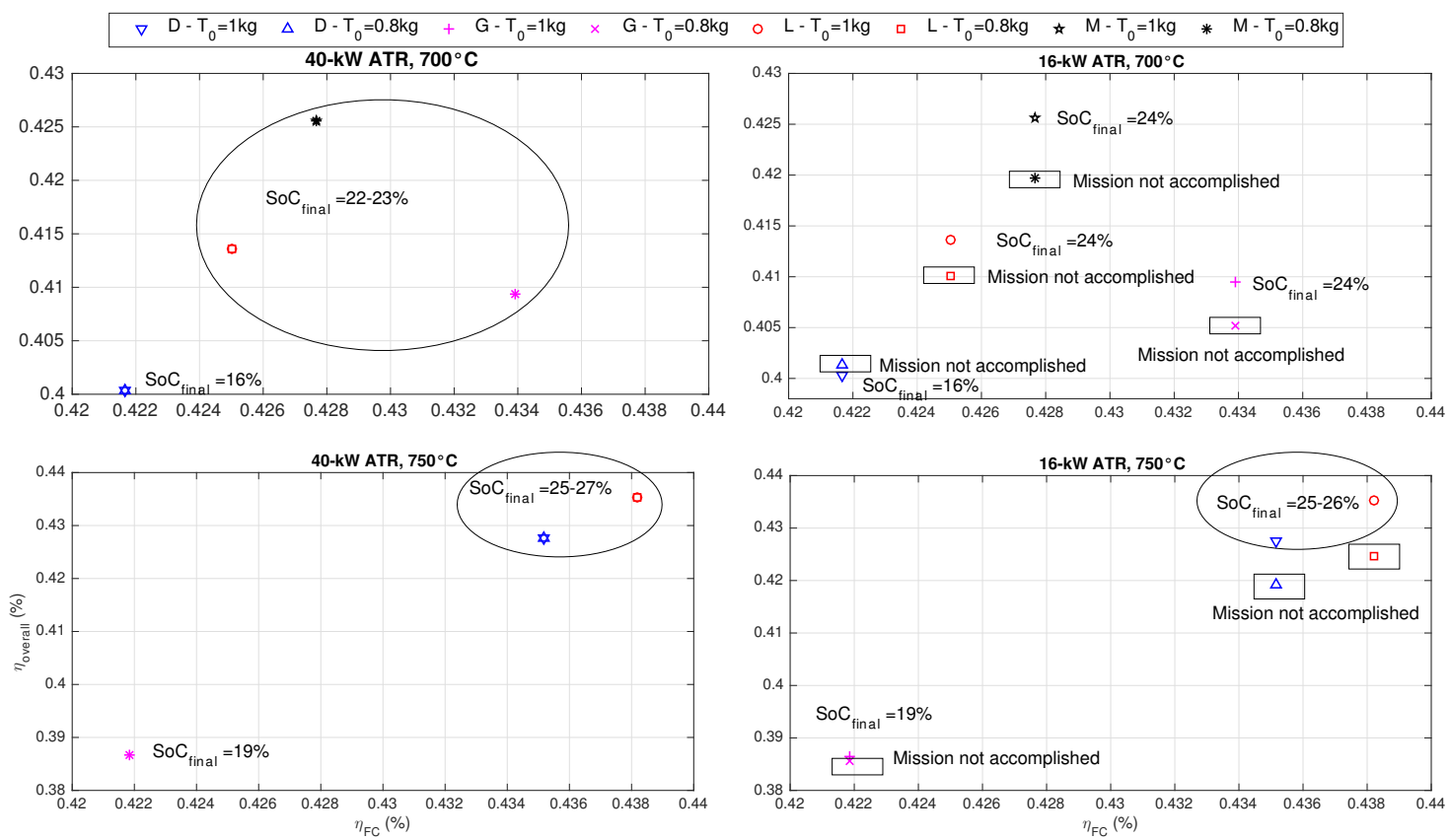

Figure 9. Vail2NREL: extra-urban driving cycle, total length $140 \mathrm{~km}$. In the legend, D = diesel, $\mathrm{G}=$ gasoline, $\mathrm{L}=\mathrm{LPG}, \mathrm{M}=$ methane. 
Things change for the $750{ }^{\circ} \mathrm{C}$ case. In fact, as one can note in Figure 6, now the gasoline-derived syngas is the one with the lowest efficiency, and this reflects on the average fuel cell efficiency portrayed in Figure 9. Moreover, when the state of charge drops below 30\%, the fuel cell is run at the maximum load in order satisfy the driver's power demand and sustain the state of charge or even recharge the battery. Since the maximum power of the gasoline-fueled FC is the lowest, the mission performed with this fuel is characterized by a final state of charge lower by $6-7 \%$ points than the other fuels. This obviously reflects on the fuel consumption, which is $10.86 \mathrm{~g} / \mathrm{km}$ for gasoline-derived hydrogen against $10.78 \mathrm{~g} / \mathrm{km}$ for diesel-derived hydrogen and $10.72 \mathrm{~g} / \mathrm{km}$ for LPG-derived hydrogen, in the case of $750{ }^{\circ} \mathrm{C}$.

In Figures 10 and 11, results are proposed for the FHDS and WLTC, and similar considerations can be done.

What is worth noting for the FHDS is that with the 40-kW ATR, any temperature, the system is able to maintain a state of charge of $30 \% \mathrm{SoC}$, and again, the markers are overlapped because the controller makes the system work exactly in the same way (i.e., with the same power split). For this driving cycle, the 16-kW ATR results in being always undersized for a working temperature of $750{ }^{\circ} \mathrm{C}$, while for a working temperature of $700^{\circ} \mathrm{C}$, only methane, LPG and diesel can allow accomplishing the mission, if the initial buffer level is $1 \mathrm{~kg}$. The system performance for the WLTC is very similar to the Vail2NREL.

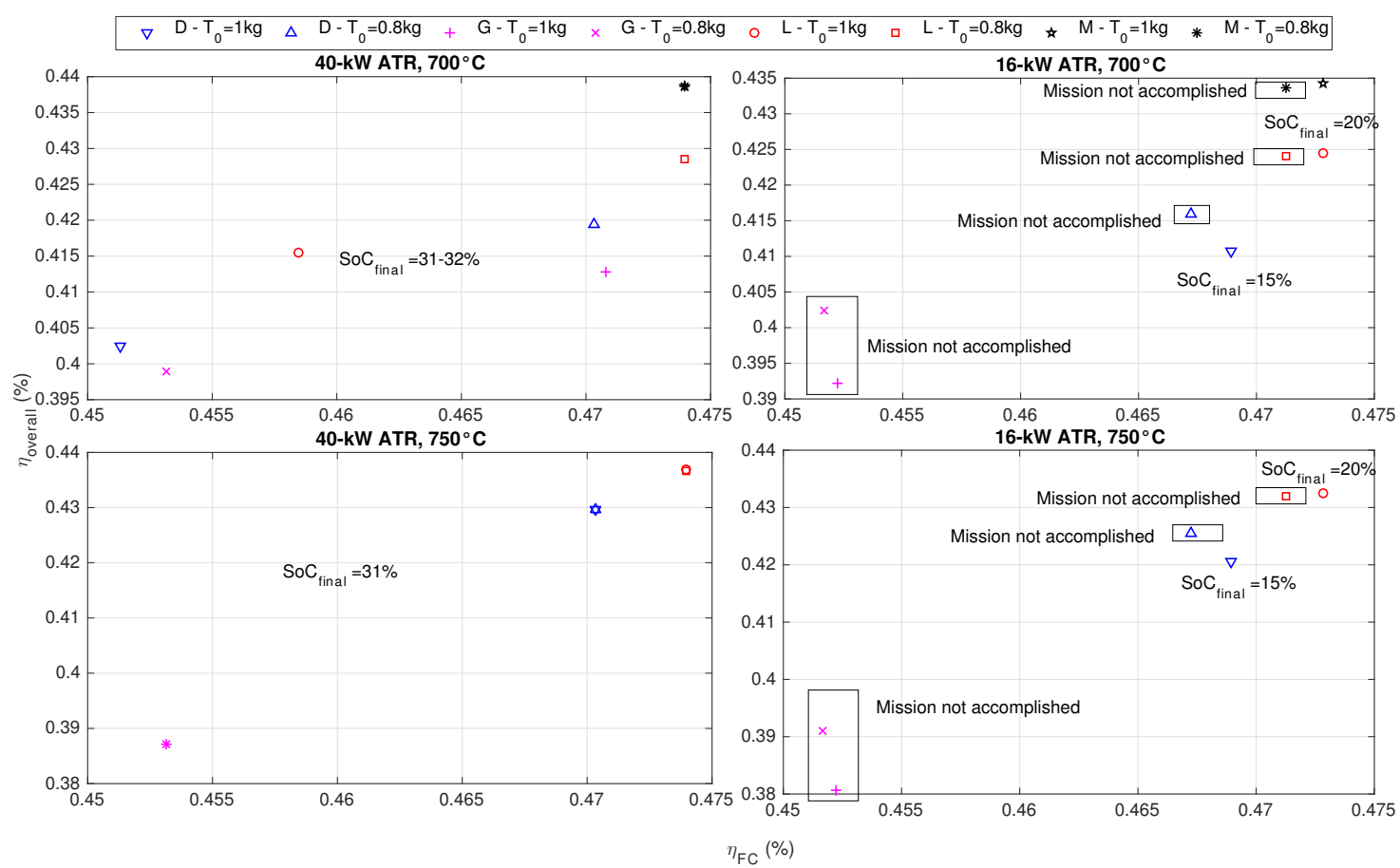

Figure 10. FHDS: Highway driving Cycle, total length $250 \mathrm{~km}$. In the legend, $\mathrm{D}=$ diesel, $\mathrm{G}=$ gasoline, $\mathrm{L}=\mathrm{LPG}, \mathrm{M}=$ methane. 


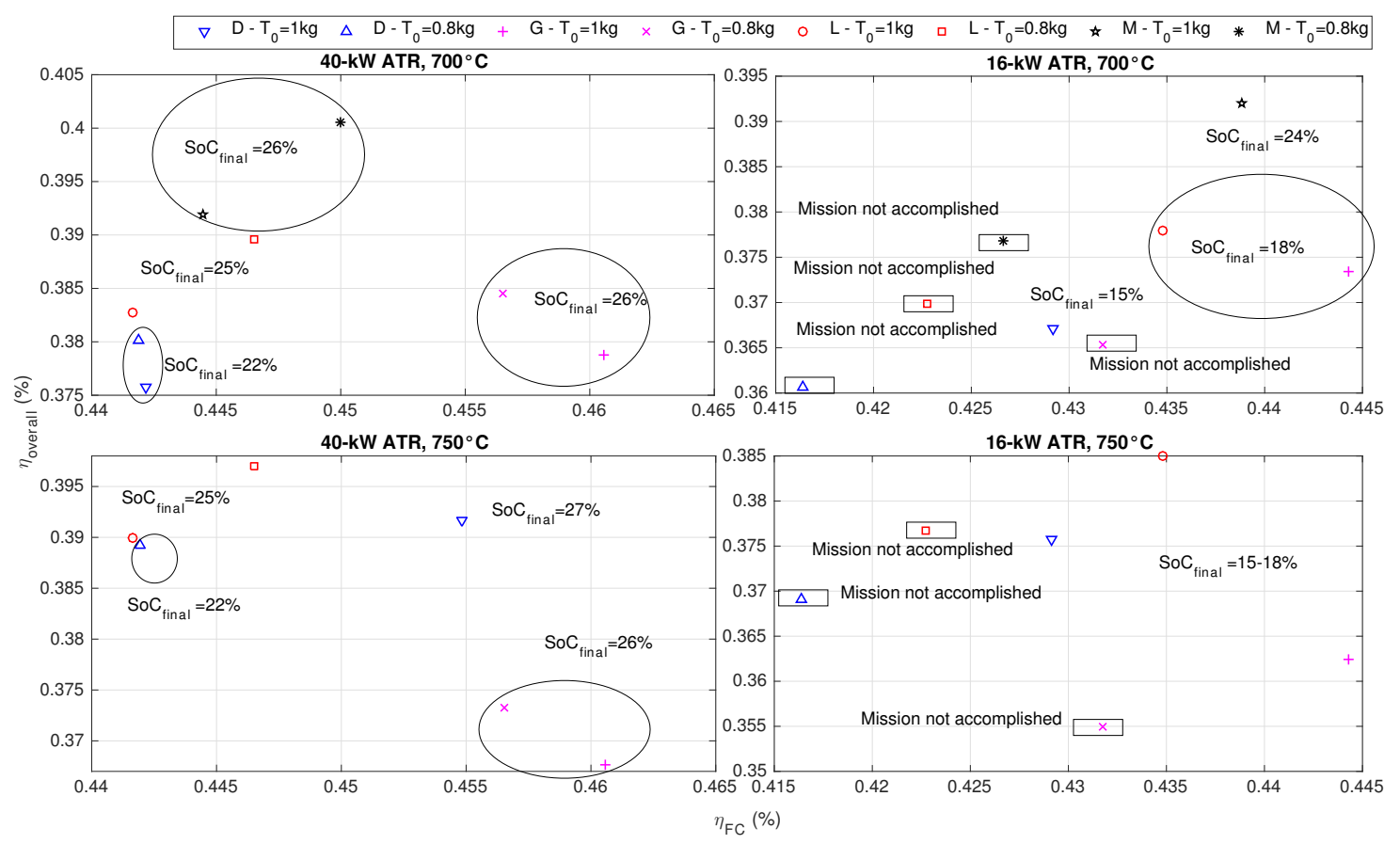

Figure 11. WLTC: combined driving cycle, total length $180 \mathrm{~km}$. In the legend, $\mathrm{D}=$ diesel, $\mathrm{G}=$ gasoline, $\mathrm{L}=\mathrm{LPG}, \mathrm{M}=$ methane.

By comparing all of the missions, it is possible to conclude that a 40-kW ATR is oversized for an urban pattern, but necessary for extra-urban, highway or combined missions, which in several cases cannot be accomplished with 16-kW ATR, even if the buffer is completely full. The issue related to the impossibility of switching off the ATR, because of the very long warm-up time needed to re-switch it on, makes the 40-kW ATR system very inefficient in low-demanding driving cycles as the fuel cell must be used to consume hydrogen as the hydrogen buffer is always completely full. This aspect might be solved by asking the driver to select the mission typology before starting his/her trip. With respect to the working temperature of the ATR, besides the gasoline, all of the other fuels allow for a higher overall efficiency at $750{ }^{\circ} \mathrm{C}$. Nevertheless, the benefit of using the system at this temperature does not justify the loss of possibility of using methane, which is also the fuel that produces the syngas with the lowest content of $\mathrm{CO}$ and $\mathrm{CO}_{2}$ compounds (see Table 2) and with the highest conversion efficiency.

The obtained fuel consumptions can also be compared to the ones of fuel cell vehicles of the same class currently available on the market. Toyota FCHV-adv has a declared consumption of 43 MPGe (MPGe stands for miles per gallon gasoline equivalent, where the energy of one gallon of gasoline is considered to be equal to $33.7 \mathrm{kWh}$ [30]) in highway conditions, with a total range of 500 miles, and 39 MPGe with a total range of $400 \mathrm{~km}$ in city driving conditions [30]. In order to make a comparison, the vehicle simulator with the 40-kW ATR and an 80-L fossil fuel tank has been used to simulate a 495-mile FHDS and a 398-mile Artemis urban driving cycle. Regardless of the fuel type, the vehicle results are able to accomplish both missions.

For the FHDS, the FCV gives a maximum fuel consumption of 46.8 MPGe with diesel-derived hydrogen ( $24 \mathrm{~L}$ of diesel and hydrogen consumed equal to $5.43 \mathrm{~kg}$ ), produced at $700{ }^{\circ} \mathrm{C}$, and a minimum fuel consumption of 49 MPGe (hydrogen consumed equal to $5.31 \mathrm{~kg}$ ) with LPG-derived hydrogen, produced at $700{ }^{\circ} \mathrm{C}$. With gasoline-derived hydrogen, the consumption is equal to $5.18 \mathrm{~kg}$, corresponding to $25 \mathrm{~L}$ of gasoline and $48 \mathrm{MPGe}$. It is worth noting that, the fuel tank having a volume of $80 \mathrm{~L}$, the vehicle maximum range is of around $1500 \mathrm{~km}$ for diesel, $1400 \mathrm{~km}$ for gasoline and $1100 \mathrm{~km}$ for LPG. By fueling the tank with methane, instead, this range is not achievable, since the required hydrogen should be equal to $5.26 \mathrm{~kg}$, which corresponds to $84.4 \mathrm{~L}$ of methane at the delivery pressure typical of a gas station, i.e., 250 bar [31]. When the tank is filled with methane, the vehicle has a range 
of $470 \mathrm{~km}$, under the FHDS driving cycle, consuming $4.96 \mathrm{~kg}$ of hydrogen with a fuel consumption of 51 MPGe. Therefore, the vehicle has better overall performance than the vehicle taken as the reference.

For the Artemis urban, the FCV gives a maximum fuel consumption of 29.9 MPGe with gasoline-derived hydrogen ( $33 \mathrm{~L}$ of gasoline and $6.85 \mathrm{~kg}$ of hydrogen consumed), produced at $700{ }^{\circ} \mathrm{C}$ and a minimum fuel consumption of $30.1 \mathrm{MPGe}$ ( $43 \mathrm{~L}$ of LPG and hydrogen consumed equal to $7.02 \mathrm{~kg}$ ) with LPG-derived hydrogen, produced at $700{ }^{\circ} \mathrm{C}$. With diesel-derived hydrogen, the consumption is equal to $6.82 \mathrm{~kg}$, corresponding to $31 \mathrm{~L}$ of diesel and $30 \mathrm{MPGe}$. Again, the maximum range is definitely higher than the vehicle taken as a reference, being around $1000 \mathrm{~km}$ with gasoline and diesel and $700 \mathrm{~km}$ for LPG. For the methane, the same issue mentioned above holds, since $7.04 \mathrm{~kg}$ of hydrogen would require $113 \mathrm{~L}$ of methane. With this fuel, the vehicle has a maximum range of $252 \mathrm{~km}$, under the Artemis urban driving cycle, with a fuel consumption of 27 MPGe. The results obtained for the urban pattern confirm the weakness of the ATR oversizing, when constraints on the reactor on/off time and hydrogen buffer level hold. Nonetheless, the result is still comparable with a real vehicle fueled by hydrogen and may be justified by the advantage of being not affected by the lack of hydrogen infrastructures.

\section{Conclusions}

In this paper, the capabilities of a fuel cell hybrid vehicle with an on-board autothermal reformer to cope with different fuels at different operating conditions have been investigated. As first, all of the ATR maps as a function of the processed fuel have been presented, and afterwards, two temperature levels where the ATR can operate within certain constraints have been selected. A plausible operating subset has been chosen, which would meet constraints on the $\mathrm{CO}$ concentration and the S/C ratio in order to maximize conversion efficiency, while reducing the CO poisoning effect on HTPEM FC. After having chosen the operating points for the ATR, it has been possible to evaluate the performance of the HTPEM FC, modeled by means of a semi-empirical electrochemical model, for every fuel and the two considered ATR temperatures. Results were compared by means of a complete vehicle model, which allowed studying the system behavior along different driving cycles and to evaluate its capability to mitigate the effect of operating the ATR at the same temperature and S/C ratio, when fed by different fuels. Two different sizes for the ATR have been considered, and the pros and cons have been analyzed. In particular, it was pointed out how the power level chosen for the ATR during the design phase may have a strong impact on the FCV range. In fact, if a small ATR could be sufficient for a urban driving cycle, despite the presence of a hydrogen buffer, it would not be enough for a more high-demanding driving cycle. On the other hand, a too large ATR would lead to a higher fuel consumption during low-load cycles, being compelled to empty the hydrogen buffer even if it would assure the accomplishment of a more demanding cycle. The warm up time of the ATR, which imposes constraints on its maximum shutdown duration, is still the major issue of an on-board reformer, as it can sometimes force the powertrain to "consume" hydrogen to preserve the buffer integrity. Nonetheless, by comparing the results with a fuel cell vehicle already available on the market, it is possible to note that this system is able to achieve comparable and even better performance with three out of four of the selected fuels. Only methane, despite having the highest conversion efficiency, has a significantly reduced range, due to the delivery density at the gas station, which limits the storable quantity. Diesel, gasoline and LPG allow achieving definitely higher ranges in every case, with a lower fuel consumption for the extra-urban and highway driving conditions and a greater fuel consumption, but still acceptable for the urban pattern. Obviously, the major drawbacks to be solved are still the high investment costs and the space requirements of the entire powertrain.

Author Contributions: Laura Tribioli realized the Matlab/Simulink simulator and designed the control strategy; Raffaello Cozzolino performed the ATR design and optimization with Aspen Plus; Daniele Chiappini realized the HTPEM simulation code and derived the performance curves; Laura Tribioli, Raffaello Cozzolino and Daniele Chiappini performed the analyses and analyzed the data; and Laura Tribioli, Raffaello Cozzolino and Daniele Chiappini wrote the paper. 
Conflicts of Interest: The authors declare no conflict of interest.

\section{References}

1. Roskilly, A.P.; Palacin, R.; Yan, J. Novel technologies and strategies for clean transport systems. Appl. Energy 2015, 157, 563-566.

2. Chan, C.C. The state of the art of electric, hybrid, and fuel cell vehicles. Proc. IEEE 2007, 95, 704-718.

3. Lacandia, F.; Tribioli, L.; Onori, S.; Rizzoni, G. Adaptive energy management strategy calibration in PHEVs based on a sensitivity study. SAE Int. J. Altern. Powertrains 2013, 2, 443-455.

4. Ahmed, A.; Al-Amin, A.Q.; Ambrose, A.F.; Saidur, R. Hydrogen fuel and transport system: A sustainable and environmental future. Int. J. Hydrog. Energy 2016, 41, 1369-1380.

5. Purnima, P.; Jayanti, S. A high-efficiency, auto-thermal system for on-board hydrogen production for low temperature PEM fuel cells using dual reforming of ethanol. Int. J. Hydrog. Energy 2016, 41, 13800-13810.

6. Pettersson, L.J.; Westerholm, R. State of the art of multi-fuel reformers for fuel cell vehicles: Problem identification and research needs. Int. J. Hydrog. Energy 2001, 26, 243-264.

7. Brown, L.F. A comparative study of fuels for on-board hydrogen production for fuel-cell-powered automobiles. Int. J. Hydrog. Energy 2001, 26, 381-397.

8. Thomas, C.E.; James, B.D.; Lomax, F.D.; Kuhn, I.F. Fuel options for the fuel cell vehicle: Hydrogen, methanol or gasoline? Int. J. Hydrog. Energy 2000, 25, 551-567.

9. Larminie, J.; Lowry, J. Front Matter, in Electric Vehicle Technology Explained, Second Edition; John Wiley \& Sons, Ltd.: Chichester, UK, 2012.

10. Bowers, B.J.; Zhao, J.L.; Ruffo, M.; Khan, R.; Dattatraya, D.; Dushman, N.; Beziat, J.C.; Boudjemaa, F. Onboard fuel processor for PEM fuel cell vehicles. Int. J. Hydrog. Energy 2007, 32, 1437-1442.

11. Chrenko, D.; Gao, F.; Bluier, B.; Bouquain, D.; Miraoui, A. Methanol fuel processor and PEM fuel cell modeling for mobile application. Int. J. Hydrog. Energy 2010, 35, 6863-6871.

12. Xu, X.; Li, P.; Shen, Y. Small-scale reforming of diesel and jet fuels to make hydrogen and syngas for fuel cells: A review. Appl. Energy 2013, 108, 202-217.

13. Jaggi, V.; Jayanti, S. A conceptual model of a high-efficiency, stand-alone power unit based on a fuel cell stack with an integrated auto-thermal ethanol reformer. Appl. Energy 2013, 110, 295-303.

14. Cozzolino, R.; Chiappini, D.; Tribioli, L. A Numerical Model for CO Effect Evaluation in HT-PEMFCs: Part 1-Experimental Validation; American Institute of Physics: College Park, MD, USA, 2016; Volume 1738.

15. Cozzolino, R.; Chiappini, D.; Tribioli, L. A Numerical Model for CO Effect Evaluation in HT-PEMFCs: Part 2-Application to Different Membranes; American Institute of Physics: College Park, MD, USA, 2016; Volume 1738.

16. Ercolino, G.; Ashraf, M.A.; Specchia, V.; Specchia, S. Performance evaluation and comparison of fuel processors integrated with PEM fuel cell based on steam or autothermal reforming and on CO preferential oxidation or selective methanation. Appl. Energy 2015, 143, 138-153.

17. Martin, S.; Wörner, A. On-board reforming of biodiesel and bioethanol for high temperature PEM fuel cells: Comparison of autothermal reforming and steam reforming. J. Power Sources 2011, 196, 3163-3171.

18. Andreasen, S.J.; Ashworth, L.; Sahlin, S.; Jensen, H.C.B.; Kær, S.K. Test of hybrid power system for electrical vehicles using a lithium-ion battery pack and a reformed methanol fuel cell range extender. Int. J. Hydrog. Energy 2014, 39, 1856-1863.

19. Zhang, J.; Xie, Z.; Zhang, J.; Tang, Y.; Song, C.; Navessin, T.; Shi, Z.; Song, D.; Wang, H.; Wilkinson, D.P.; et al. High temperature PEM fuel cells. J. Power Sources 2006, 160, 872-891.

20. Tribioli, L.; Cozzolino, R.; Chiappini, D.; Iora, P. Energy management of a plug-in fuel cell/battery hybrid vehicle with on-board fuel processing. Appl. Energy 2016, 184, 140-154.

21. Ersoz, A.; Olgun, H.; Ozdogan, S. Reforming options for hydrogen production from fossil fuels for PEM fuel cells. J. Power Sources 2006, 154, 67-73.

22. Jin, Y.; Rui, Z.; Tian, Y.; Lin, Y.; Li, Y. Sequential simulation of dense oxygen permeation membrane reactor for hydrogen production from oxidative steam reforming of ethanol with ASPEN PLUS. Int. J. Hydrog. Energy 2010, 35, 6691-6698.

23. Yang, G.; Yu, H.; Peng, F.; Wang, H.; Yang, J.; Xie, D. Thermodynamic analysis of hydrogen generation via oxidative steam reforming of glycerol. Renew. Energy 2011, 36, 2120-2127. 
24. Tzanetis, K.; Martavaltzi, C.; Lemonidou, A. Comparative exergy analysis of sorption enhanced and conventional methane steam reforming. Int. J. Hydrog. Energy 2012, 37, 16308-16320.

25. Gangadharan, P.; Kanchi, K.C.; Lou, H.H. Evaluation of the economic and environmental impact of combining dry reforming with steam reforming of methane. Chem. Eng. Res. Des. 2012, 90, 1956-1968.

26. Perna, A. Hydrogen from ethanol: Theoretical optimization of a PEMFC system integrated with a steam reforming processor. Int. J. Hydrog. Energy 2007, 32, 1811-1819.

27. Cozzolino, R.; Tribioli, L. On-Board Diesel Autothermal Reforming For PEM Fuel Cells: Simulation and Optimization; American Institute of Physics: College Park, MD, USA, 2015; Volume 1648.

28. Minutillo, M. On-board fuel processor modeling for hydrogen-enriched gasoline fueled engine. Int. J. Hydrog. Energy 2005, 30, 1483-1490.

29. Tribioli, L.; Cozzolino, R.; Barbieri, M. Optimal Control of a Repowered Vehicle: Plug-in Fuel Cell against Plug-in Hybrid Electric Powertrain; American Institute of Physics: College Park, MD, USA, 2015; Volume 1648.

30. Das, H.S.; Tan, C.W.; Yatim, A. Fuel cell hybrid electric vehicles: A review on power conditioning units and topologies. Renew. Sustain. Energy Rev. 2017, 76, 268-291.

31. Alternative Fuels Data Center. Available online: http://www.afdc.energy.gov/vehicles/natural_gas_filling_ tanks.html (accessed on 16 May 2017).

(C) 2017 by the authors. Licensee MDPI, Basel, Switzerland. This article is an open access article distributed under the terms and conditions of the Creative Commons Attribution (CC BY) license (http:/ / creativecommons.org/licenses/by/4.0/). 